Çukurova Üniversitesi Mühendislik Mimarlık Fakültesi Dergisi, 33(4), ss. 175-184, Aralık 2018

Çukurova University Journal of the Faculty of Engineering and Architecture, 33(4), pp. 175-184, December 2018

\title{
Tek Taraflı Isıtmaya Maruz Yüksek Şekil Oranlı Minikanallarda Pasif Akış Kontrol Yöntemi Kullanılarak Isı Transferinin İyileştirilmesi
}

\author{
Erhan FIRAT ${ }^{* 1}$ \\ ${ }^{1}$ Munzur Üniversitesi, Mühendislik Fakültesi, Makine Mühendisliği Bölümü, Tunceli
}

Geliş tarihi: 08.05.2018～Kabul tarihi: 25.12 .2018

$\ddot{\mathbf{O z}}$

Pasif akış kontrol silindirinin olduğu ve olmadığı durumlarda, bir geniş yüzeyinden 1sttılan dar, dikdörtgen şeklindeki bir minikanal içerisindeki taşınımla 1sı transferi durumunun hesaplamalı akışkanlar dinamiği (HAD) benzetiminin sonuçları rapor edilmiştir. Silindirin çapı $(d)$, kanal yüksekliğinin $(t)$ yaklaşık olarak onda biri kadardır. Bu çalışmanın amacı, 1sıtılan kanal duvarı ve silindirin merkezi arasındaki üç farklı mesafeyi $(s)$ çalışarak, pasif kontrol silindirinin sistemin ısıl performansı üzerindeki etkisini anlamaktır. Test edilen boyutsuz mesafelere $(s / t)$ bakılmaksızın, pasif kontrol silindirinin mevcudiyetinde sistemin ısıl performansının iyileştiği bulunmuştur. Bu, üniform 1sı akısına maruz kalan yüzey üzerindeki hidrodinamik sınır tabaka ile sırayla büyük-ölçekli çevrilere dökülen, silindirden olan serbest kayma tabakalarının şiddetli etkileşimlerine dayandırılmıştır.

Anahtar Kelimeler: Isı transferi iyileştirilmesi, Pasif akış kontrolü, Minikanal, HAD

\section{Heat Transfer Enhancement in a High Aspect Ratio Minichannel Heated on one Side Using a Passive Flow Control Method}

\begin{abstract}
The results of computational fluid dynamics (CFD) simulation for convective heat transfer in a narrow rectangular minichannel heated on one large side, with and without the presence of passive flow control cylinder, are reported. The diameter of the cylinder $(d)$ is approximately one tenth of the height of the channel $(t)$. The objective of this study is to understand the effect of the passive control cylinder on thermal performance of the system by studying three different distances $(s)$ between the heated channel wall and the center of the cylinder. It was found that the thermal performance of the system enhanced in the presence of the passive control cylinder regardless of non-dimensional distances $(s / t)$ tested. This was attributed to the strong interactions between free shear layers from the cylinder that alternately shed largescale vortices and hydrodynamic boundary layer on the surface that is subjected to a uniform heat flux.
\end{abstract}

Keywords: Heat transfer enhancement, Passive flow control, Minichannel, CFD

*Sorumlu yazar (Corresponding author): Erhan FIRAT, efirat@munzur.edu.tr 
Tek Taraflı Isıtmaya Maruz Yüksek Şekil Oranlı Minikanallarda Pasif Akış Kontrol Yöntemi Kullanılarak Isı Transferinin Iyileştirilmesi

\section{GíRiş}

Malzeme test reaktörü (Materials Testing Reactor, MTR), yoğun nötron 1şınımının meydana getirdiği bir akışın belirli bir malzeme üzerinde oluşturulması sonucu, yakıt ve malzemenin nasıl davranışlar sergilediğini görmemizi sağlayan çok yönlü bir araştırma istasyonudur. Nötron bombardımanı sonucu hem reaktör kafesinin hem de nötron yansıtıcının soğutulması gerekmektedir. $\mathrm{Bu}$ reaktör için geliştirilen plaka-tipli, kısa aralıklarla yerleştirilmiş yakıt elementlerinin kullanımı, soğutucu akışkanı dar kesitli (yüksek şekil oranına sahip) kanallardan geçmeye zorlamaktadır [1]. Şekil oranı $(A R)$, dikdörtgen bir kanal için Eşitlik 1'deki gibi ifade edilebilir.

$$
\mathrm{AR}=\frac{\mathrm{w}}{\mathrm{t}}
$$

Burada $w$ kanal genişliğini, $t$ ise kanal yüksekliğini ifade etmektedir. Forrest ve arkadaşları [1] yüksek şekil oranına sahip bir dikdörtgen kanalı (26:1) bir geniş yüzeyinden 1sıtarak, hem geçiş hem de türbülanslı akış rejimlerinin hakim olduğu iç akış durumlarını içeren belirli bir Reynolds sayısı aralığ $1(4000<R e<70000)$ ve belirli bir Prandtl sayıs1 aralığı $(2,2<P r<5,4)$ için basınç düşüşüne bağlı sürtünme faktörünün $(f)$ ve Nusselt sayısının $(\mathrm{Nu})$ değişimlerini göstermişler ve kanal boyunca olan zaman-ortalamalı Nusselt sayısı $\left(N u_{\text {ort }}\right)$ için ampirik ve yarı-analitik bağıntılar sunmuşlardır. Bu çalışmanın amacı ise, Forrest ve arkadaşlarının [1] sunmuş olduğu deneysel verilerden faydalanarak aynı şartlar altında akışın benzetimini (simülasyon) yapmak, sonuçları kıyaslamak, sonrasında ise kanal içerisinde önceden belirlenmiş üç farklı konuma sırasıyla yerleştirilen sabit dairesel silindir yardımı ile akışa belirli bölgelerde müdahalelerde bulunarak, sistemin 1 s1 performansını iyileştirmektir. Bu sayısal çalışma, tam gelişmiş türbülanslı akışın hakim olduğu, kanal hidrolik çapına ( $\left.D_{\text {hid }}\right)$ bağlı tek bir $R e$ 'de (20000) gerçekleştirilmiştir.

\section{2. ÖNCEKİ ÇALIŞMALAR}

Pasif çevri üreteçleri, kanatçıklar, yüzey çıkıntıları ve yüzey oyukları ile kimya, otomotiv ve elektronik endüstrisindeki birçok uygulama için kullanılan kompakt 1sı değiştiricilerinin (eşanjör) 1sıl performanslarının iyileştirilebildiği görülmüştür. Bunu, akış içerisindeki karışımı arttırma yolu ile hidrodinamik ve isil sinır tabakaları bozarak yapabildikleri saptanmıştır. Bunu fark eden araştırmacılar farklı akış bozucu geometrileri iç akışta kullanarak onların ne denli etkinlik sağladıklarını araştırma yoluna gitmişlerdir. Bilen ve arkadaşları [2] bir dairesel en-kesitli boru içerisinden akmakta olan tam gelişmiş türbülanslı hava akışını ele alarak, boru içerisinde farklı şekillere sahip oyukların (daire, dikdörtgen, ikizkenar yamuk) olması durumunda 1S1 transferi ve sürtünme karakteristiklerinin ne tarz değişimler sergilediğini Reynolds sayısının 10000 ile 38000 aralığı için incelemişlerdir. Düz boru ile karşılaştırıldıklarında, daire şeklindeki, dikdörtgen şeklindeki ve ikizkenar yamuk şeklindeki oyukların $R e=38000$ için 1sı transferinde, sırasıyla, $\% 63, \% 47$ ve $\% 58$ 'lik iyileşmeler meydana getirdiğini belirtmişlerdir. Isıl iyileşme faktörü ya da 1sıl performans $(\eta)$, sabit pompalama gücü için iyileştirme yapılmış yüzeyin ortalama taşınım katsayısının iyileştirme öncesi durumdaki yüzeyin ortalama taşınım katsayısına oranı olarak tanımlanır ve Eşitlik 2'deki gibi ifade edilir [3].

$\eta=\left(\frac{N u_{\text {ort }}}{N u_{\text {ort }, 0}}\right)\left(\frac{f}{f_{0}}\right)^{-1 / 3}$

Oyuklu boruların, çalışılan Re için elde edilen 1sıl performanslarının 1,1 ile 1,3 arasında olduğunu da çalışmalarında belirtmişlerdir. Samadifar ve Toghraie [4], altı farklı pasif çevri oluşturucu parçanın, üçgen en kesit alanına sahip plakalı kanatlı 1S1 değiştiricisinin 1sıl performans1 üzerindeki etkilerini sayısal olarak incelemişlerdir. Dikdörtgen şekle sahip pasif çevri oluşturucu parçanın, plakalı kanatlı 1sı değiştiricisinin etkinliğini diğerlerine nazaran daha çok arttırdığını belirtmişlerdir. Promvonge ve arkadaşları [5], sabit ısı akısı uygulanan ve içerisine kıvrılmış şerit ile V-tipi kanatçık yerleştirilen bir kare en-kesitli kanalın ısıl performansındaki iyileşme durumlarını Reynolds sayısının 4000 ile 30000 değer aralığı için deneysel olarak incelemişlerdir. Kıvrılma oranının 4 olduğu şerit ile V-tipi kanatçığın 
kullanıldığı sistem için kanatçık yüksekliğinin kanal yüksekliğine oranının 0,1 ve kanatçıklar arası mesafenin şerit genişliğine oranının 2 olduğu durumda 1sıl iyileşme faktörünün en yüksek değerine eriştiği $(1,62)$ belirtilmiştir. Erişilen bu değerin, sadece kıvrılmış şeridin kullanıldığı durumda elde edilen değerden $\% 17$ daha iyi olduğu da ifade edilmiştir. Bu çalışmada ise akış bozucu eleman olarak çapı, kanal yüksekliğinin $\% 9,67$ 'si kadar olan bir adet dairesel silindir kullanılacaktır.

\section{SAYISAL METODLAR}

\subsection{Türbülans Modeli}

Minikanal içerisindeki akış ve 1Sı transferi benzetimi, yaygin kullanılan ticari bir hesaplamalı akışkanlar dinamiği (HAD) yazılımı olan ANSYS Fluent'i kullanarak daimi olmayan Reynoldsortalamalı Navier-Stokes, süreklilik ve enerji denklemlerinin çözdürülmesi sonucunda gerçekleştirilmiştir. Türbülansın modellenmesi için "Standart $k-\omega$ " modelinden faydalanılmıştır. $\mathrm{Bu}$ modelin tercih edilmesindeki iki temel unsur, istenilen parametreler için doğruluk bakımından en uygun sonuçlar sunması ve hesaplama maliyetinin istendik seviyelerde olması olarak açıklanabilir. $\mathrm{Bu}$ model kullanıldığında, türbülans kinetik enerji $(k)$ ve özgül yitim oranı $(\omega)$, sırasıyla, Eşitlik 3 ve 4'deki transport denklemlerinden elde edilir.

$$
\begin{aligned}
& \frac{\partial}{\partial t}(\rho \mathrm{k})+\frac{\partial}{\partial \mathrm{x}_{\mathrm{i}}}\left(\rho \mathrm{ku} \mathrm{u}_{\mathrm{i}}\right)= \\
& \frac{\partial}{\partial \mathrm{x}_{\mathrm{j}}}\left(\Gamma_{\mathrm{k}} \frac{\partial \mathrm{k}}{\partial \mathrm{x}_{\mathrm{j}}}\right)+\mathrm{G}_{\mathrm{k}}-\mathrm{Y}_{\mathrm{k}}+\mathrm{S}_{\mathrm{k}} \\
& \frac{\partial}{\partial \mathrm{t}}(\rho \omega)+\frac{\partial}{\partial \mathrm{x}_{\mathrm{i}}}\left(\rho \omega \mathrm{u}_{\mathrm{i}}\right)= \\
& \frac{\partial}{\partial \mathrm{x}_{\mathrm{j}}}\left(\Gamma_{\omega} \frac{\partial \omega}{\partial \mathrm{x}_{\mathrm{j}}}\right)+\mathrm{G}_{\omega}-\mathrm{Y}_{\omega}+\mathrm{S}_{\omega}
\end{aligned}
$$

Denklemde yer alan $G_{\mathrm{k}}$ ve $G_{\omega}$, sirasiyla, $k$ ve $\omega$ 'nın oluşumlarını; $\Gamma_{\mathrm{k}}$ ve $\Gamma_{\omega}$, sirasıyla, $k$ ve $\omega$ 'nın etkin yayınımlarını; $Y_{\mathrm{k}}$ ve $Y_{\omega}$, sirasiyla, $k$ ve $\omega^{\prime}$ nn yitimlerini; $S_{\mathrm{k}}$ ve $S_{\omega}$, sırasıyla, $k$ ve $\omega$ için kişi tarafindan tanımlanan kaynak terimleri temsil etmektedir. $\mathrm{Bu}$ terimlerin modellenmeleri hakkındaki detaylara, ticari HAD yazılımının kullanıcı kılavuzundan erişilebilir [6].

\subsection{Hesaplama Bölgesi ve Detaylar}

$\mathrm{Bu}$ çalışma iki temel adımdan meydana gelmektedir: 1) dikdörtgen kesitli, dar ve boş bir minikanal içerisinden düşey doğrultuda aşağıdan yukarıya doğru akan akışkana, kanalın geniş bir yüzeyinden olan 1sı transferi durumunu modelleyip yeterli doğrulukta çıktılar elde etmek, 2) kanal içerisinde önceden belirlenen boyutsuz mesafelere sırayla dairesel silindiri yerleştirerek, sistemin isıl performansındaki değişimleri irdelemek. Hesaba katılan fiziksel bölge ve sınır şartları Şekil 1'de verilmiştir. Dean [7], bir kanalın şekil oranının 7'den büyük olduğu durumlarda, kanal içinden olan akışın iki-boyutlu (2B) olarak kabul edilebileceğini bildirmiştir. $\mathrm{Bu}$ oran Forrest ve arkadaşları [1] için 26 olduğundan, bu çalışmadaki kanalın 2B olabileceğine kanaat getirilmiştir. Kanal, Kandlikar ve Grande'nin [8] yapmış olduğu sınıflandırmaya göre minikanal sınıfında yer almaktadır.

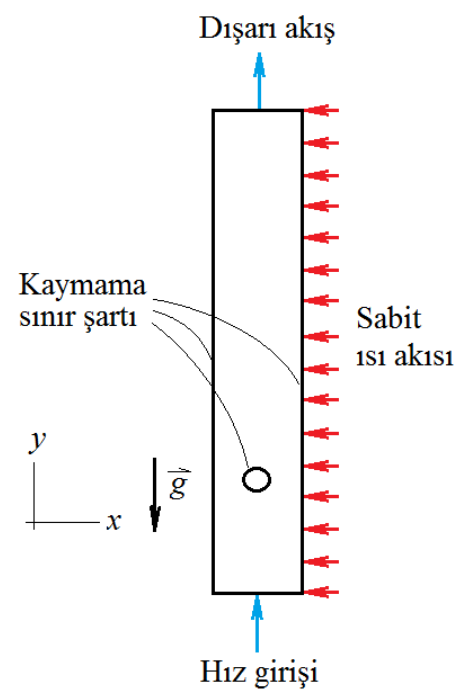

Şekil 1. İki-boyutlu fiziksel bölge ve atanan sınır şartları 
Dairesel silindir üzerinden akışta, çapa bağlı $R e$ 'nin yaklaşık olarak 49'u geçtiği anda bu silindirin art izi bölgesinde yer alan iki adet, birbirlerine göre ters yönde dönme hareketi yapan, sabit merkezli çevriler sırasıyla dökülmeye başlarlar. Akışa başka bir müdahale söz konusu olmadığı ve Re, 49'un altına düşmediği sürece çevri dökülme işlemi asla sekteye uğramaz [9]. $R e=1000$ için șekil oranı yüksek bir silindir etrafındaki akıs da nominal olarak 2B kabul edilebilir. Bu sebeple hesaplama bölgesi hem kanal hem de silindirin yüksek şekil oranına sahip olmasından dolayı 2B olarak tasarlanmıştır. Bu kabul, elbette, hesaplama maliyetini ciddi oranda düşürmüştür.

Hız girişi sınır şartında, ortalama hızın Re'yi 20000 yaptı̆̆ parabolik bir hiz profili tanımlanmıştır. Bu parabolik hız, fiziksel bölge için tanımlanan hidrolik çap $\left(D_{\text {hid }}=4 A / P_{\text {iç }}\right.$; burada $A$, akışkanın geçtiği kanal en-kesit alanını, $P_{\text {iç }}$ ise, bu alanın çevresini temsil etmektedir) ile aynı hidrolik çapa sahip bir kanal için ampirik bağıntılarla hesaplanan hidrodinamik giriş uzunluğunun 1,3 katından daha uzun bir borunun çıkış kısmından elde edilmiştir. Bu sınır şartı ile tam gelişmiş şekilde hesaplama bölgesine giriş yapan akışkanın yı̆̆ın sıcaklığı $T_{\text {yı̆̆ı̆ }}=30^{\circ} \mathrm{C}$ 'dir. Isı transferinin gerçekleştiği ve gerçekleşmediği geniş yüzey alanına sahip yanal duvarların kesitlerine kaymama sınır şartı atanmıştır. Bunun yanı sıra akışkana 1S1 transferinin olduğu duvara sabit 1S1 akısı sınır şartı $\left(q^{\prime \prime}>0\right)$ atanmıştır ve giriş ile çıkış yığın sıcaklıkları arasındaki farkı yaklaşık $10{ }^{\circ} \mathrm{C}$ 'ye eşit veya düşük tutacak bir 1S1 akısı değeri verilmiştir. Karşısındaki duvar adyabatiktir $\left(q^{\prime \prime}=0\right)$. Dışarı akış sınır şartı ise akışkanın hesaplama bölgesini terk eden akışkanın çıkış yaptığı sınıra ait bilgilerin, hesaplama bölgesinden elde edildiği bir sınır şartıdır. Dar kesitli kanal içerisine, 1s1 transferini iyileştirmek adına yerleştirilen silindirin yüzeyi de adyabatiktir ve buraya da kaymama sınır şartı atanmıștır. Sınır şartlar hakkındaki diğer detaylara, ticari HAD yazılımının kullanıcı kılavuzundan erişilebilir [6].

Kanal hidrolik çapına bağglı olarak $T_{\text {yı̆̆n }}=30{ }^{\circ} \mathrm{C}$ 'de elde edilen kanalın Reynols sayıs1 20000 iken silindirin çapına bağlı olarak aynı akışkan sıcaklığı değerinde elde edilen Reynolds sayısı 1000'dir. Kanal-silindir sistemi için blokaj oranı $(d / t \cdot 100)$ \%9,67'dir. Silindirin konumu ile ilgili parametreler Şekil 2 içerisinde tanımlanmıştır.

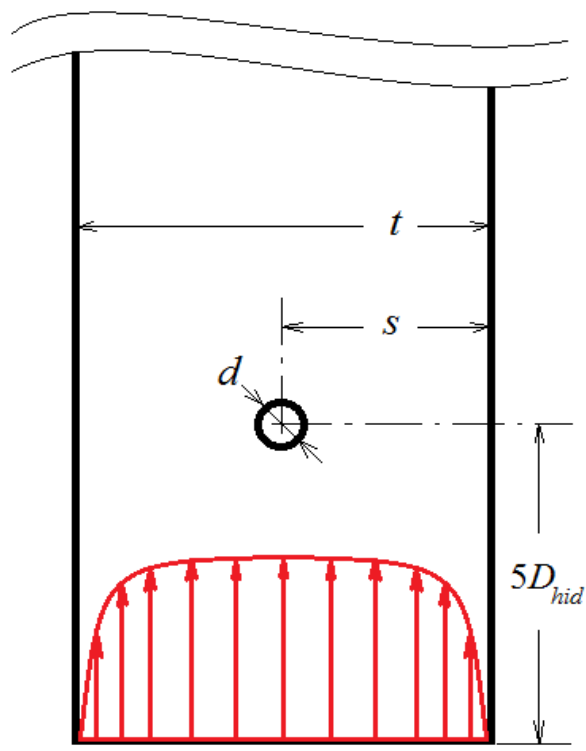

Şekil 2. Kanal başlangıç kısmında tanımlanmış bazı geometrik parametreler

Silindir merkezi, şekilden de görüleceği üzere, kanal başlangıç kesitinden akım yönünde 5 hidrolik çap kadar mesafededir. Daimi olmayan koşullar için gerçekleştirilen bu sayısal çalışma, silindir merkezi ile sabit 1s1 akısına sahip duvar aras1 boyutsuz mesafenin $(s / t) 4 / 8,3 / 8$ ve $2 / 8$ değerlerinde gerçekleştirilmiştir. Zaman adımı $(\Delta t)$ ise $R e=1000$ için dış akış durumunda, silindire ait bir çevrinin şekillenmesi için gerekli sürenin $1 / 100$ 'ü alınarak tespit edilmiştir. $\mathrm{Bu}$ değer $2,13 \times 10^{-6}$ s'ye tekabül etmektedir ve sağlıklı bir çözüm için yeterlidir. Toplam akış süresi ise $0,2 \mathrm{~s}$ olacak şekilde ayarlanmıştır. Bu akış süresiyle, ortalama akış hızına sahip bir akışkan parçacığı, kanal başlangıç kısmından başlayarak, toplam kanal uzunluğunun 2,73 katı yol alabilir. Akış alanı, gerek içerisinde silindirin bulunmadığı ağdan bağımsızlık testlerinde olsun gerekse içerisinde silindirin bulunduğu esas testlerde olsun, eş açılı çarpıklık oranı 0,5 'in altına düşmediği yapılandırılmış dörtgen ağlarla oluşturulmuştur (Şekil 3). 


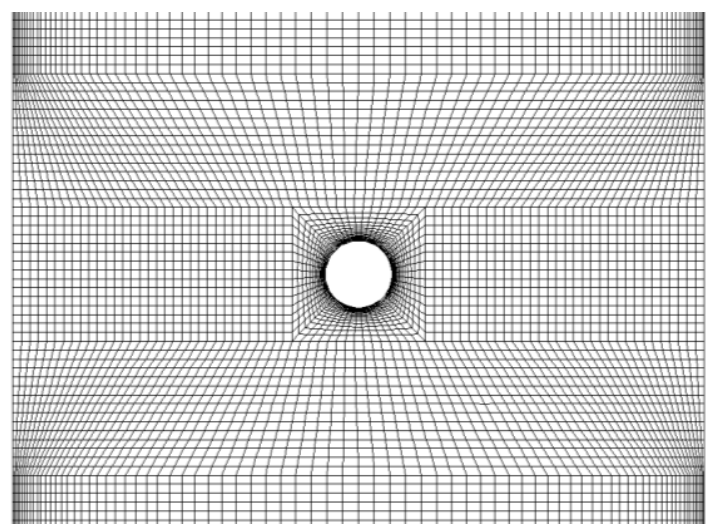

Şekil 3. Kanal içerisine yerleştirilen dairesel silindir etrafındaki ağ yapısının bir görüntüsü

Yine çözüm kalitesini arttırmak adına, gerek silindir yüzeyinde gerekse kanal yüzeylerinde yer alan ağlardan yüzeye normal yönde yer alan ilk sekizinin sayıları dört kat artırılmıştır.

Sayısal çalışma içerisinde görüleceği üzere akışkana 1Sı transferi söz konusudur ve bundan dolay1 kontrol hacimlerinin yerel sicaklıkları hesaplamalar sonucunda farklılık gösterecektir. $\mathrm{Bu}$ sıcaklık farklılığının akışkan akışı üzerindeki etkilerini iyi bir şekilde görebilmek için, $25^{\circ} \mathrm{C}$ ile $85^{\circ} \mathrm{C}$ arasında, akışkan yoğunluğunun $(\rho)$, özgül 1sısının $\left(c_{\mathrm{P}}\right)$, 1S1 iletim katsayısının $(k)$ ve dinamik viskozitesinin $(\mu)$ sıcaklığa bağlı değişimlerini veren deneysel verilerden faydalanarak, yukarıda adı geçen her bir parametre için eğriler uydurulmuştur. Uydurulan bu eğrilere (parabol) ait denklemlerin katsayıları da benzetim programı içerisine eklenmiştir [10]. Kısacası, bu benzetim içerisinde kullanılan akışkanın termofiziksel özellikleri sıcaklığa bağlı değişim sergilemektedir.

\subsection{Ağdan Bağımsızlık}

Gerçekleştirilmesi planlanan sayısal çalışma için öngörülen ă̆ sayısının ne olması gerektiği, dört farklı ağ sayısı değerine sahip boş kanal (silindirsiz) için elde edilen $f$ ve $N u_{\text {ort }}$ değerlerinin değişim oranlarını karşılaştırarak elde edilecektir. Karşılaştırmalar sonucunda, şayet ilgili parametrelerin her ikisinde de meydana gelen değişimler \%2 civarı veya altında kalırsa, o ağ sayısı temel alınarak pasif akış kontrol silindirinin bulunduğu modeller kurulacaktır. Farklı ağ sayılarından meydana gelen fiziksel modellerden elde edilen veriler Çizelge 1'de verilmiştir.

M1 nolu modelden M2 nolu modele geçildiğinde $f$ ve $N u_{\text {ort }}$ için elde edilen değerler arasındaki değişimler, sırasıyla, \%4,94 ve \%6,13'tür. M2 nolu modelden M3 nolu modele geçildiğinde $f$ ve $N u_{\text {ort }}$ için elde edilen değerler arasındaki değişimler, sırasıyla, \%2,61 ve \%3,59'dur. M4 nolu modele geçildiğinde ise $f$ ve $N u_{\text {ort }}$ için elde edilen değerler arasındaki değişimler, sırasıyla, $\% 1,55$ ve \%2,03'tür. $\mathrm{Bu}$ değişimler temel alındığında, 1536000 ağ sayısına sahip M4 modelinin, bu çalışma için uygun şartları sağladığı açıkça görülmektedir. $\mathrm{Bu}$ sebeple, gerçekleştirilmesi planlanan testler için bu model kullanılacaktır.

Çizelge 1. Farklı ağ sayısına sahip modellerden elde edilen veriler (A ğdan bağımsızlık testi)

\begin{tabular}{|c|c|c|c|}
\hline Model no & Ăg sayısı & $f$ & $N u_{\text {ort }}$ \\
\hline M1 & 204000 & 0,02484 & 114,43 \\
\hline M2 & 528000 & 0,02613 & 121,90 \\
\hline M3 & 972000 & 0,02683 & 126,44 \\
\hline M4 & 1536000 & 0,02725 & 129,06 \\
\hline
\end{tabular}

\subsection{Tasdikleme Çalışmaları}

Bilindiği üzere tasdikleme (validation) çalışmaları, sayısal modelin gerçeği ne derece yansıttı̆̆ını gösterirler ve her HAD çalışmasında bulunması gereken önemli bir unsurdur. $\mathrm{Bu}$ çalışmada, $R e=20000$ için M4 nolu fiziksel modelden elde edilen $f$ ve $N u_{\text {ort }}$ değerleri, aynı $R e$ için diğer ampirik bağıntılardan, analitik bağıntılardan ve deneysel çalışmalardan elde edilen değerler ile kiyaslanacaktır.

Blasius [11], pürüzsüz bir boruda tam gelişmiş türbülanslı akışın olduğu durumda (Re>3000 için geçerli) sürtünme faktörünün hesaplanması için Eşitlik 5'i önermiştir.

$$
\mathrm{f}=0,3164 \mathrm{Re}^{-0,25}
$$


Tek Taraflı Isıtmaya Maruz Yüksek Şekil Oranlı Minikanallarda Pasif Akış Kontrol Yöntemi Kullanılarak Isı Transferinin Iyileştirilmesi

Boru içi boyutsuz pürüzlülüğe ve $R e$ 'ye bağlı olarak verilen kapalı Colebrook denkleminin pürüzsüz borular için uyarlanmış hali (Prandtl denklemi) Eşitlik 6'daki gibidir [12].

$$
\frac{1}{\sqrt{\mathrm{f}}}=-2,0 \log \left(\frac{2,51}{\operatorname{Re} \sqrt{\mathrm{f}}}\right)
$$

Gnielinski [13], dairesel kesitli borularda tek fazlı akış durumunda 1 sı transferi oranını saptayabilmek için Eşitlik 7'yi önermiştir.

$$
\mathrm{Nu}_{\mathrm{ort}}=\frac{(\mathrm{f} / 8)(\mathrm{Re}-1000) \operatorname{Pr}}{1+12,7 \sqrt{\mathrm{f} / 8}\left(\operatorname{Pr}^{2 / 3}-1\right)}
$$

$\mathrm{Bu}$ denklem $2100<R e<5 \times 10^{6}$ ve $0,5<P r<2000$ için geçerlilik sağlamaktadır. Bu denklemde yer alan $f$ değerinin, aşağıda, pürüzsüz dairesel kesitli borular için Petukhov [14] tarafindan verilen Eşitlik 8 ile belirlenmesi önerilmektedir.

$$
\mathrm{f}=\left[1,82 \log _{10}(\mathrm{Re})-1,64\right]^{-2}
$$

Yukarıda verilen bağıntılar ve Forrest ve arkadaşlarının [1] deneysel çalışmaları göz önüne alındığında, $R e=20000$ için elde edilen $f$ ve $N u_{\text {ort }}$ değerleri, kıyaslama maksadıyla, Çizelge 2 içerisinde sunulmuştur. Görüleceği üzere bu çalışmadan elde edilen $f$ değeri, ampirik ve yarı analitik bağıntılar ile elde edilen değerlerden hafifçe fazla olmasına karşın deneysel olarak elde edilen $f$ ve $N u_{\text {ort }}$ aralığının sınırları içerisinde yer almaktadir.

Çizelge 2. Farklı kaynaklardan $R e=20000$ için toparlanan $f$ ve $N u_{\text {ort }}$ değerleri

\begin{tabular}{|c|c|c|c|}
\hline Kaynak & Denklem & $\boldsymbol{f}$ & $\boldsymbol{N} \boldsymbol{u}_{\text {ort }}$ \\
\hline$[11]$ & $(5)$ & 0,02661 & - \\
\hline$[12]$ & $(6)$ & 0,02588 & - \\
\hline$[14]$ & $(8)$ & 0,02612 & - \\
\hline $\begin{array}{c}\text { Mevcut } \\
\text { calşsma } \\
\text { (Sayisal) }\end{array}$ & - & 0,02725 & 129,06 \\
\hline $\begin{array}{c}{[1]} \\
\text { (Deneysel) }\end{array}$ & - & $\begin{array}{c}0,02703- \\
0,02970\end{array}$ & $\begin{array}{c}125,41- \\
155,84\end{array}$ \\
\hline$[13]$ & $(7)$ & - & 134,90 \\
\hline \multicolumn{4}{|c|}{} \\
\hline
\end{tabular}

\section{4. ÇIKTILAR VE İRDELENMESI}

Düzleme dik eksene ait anlık çevrinti vektörünün büyüklüğü, test edilen üç farklı boyutsuz mesafe değerine bağlı olarak Şekil 4'te verilmiştir. Şekil 4'de yer alan $\mathrm{x} / \mathrm{t}$ ve $\mathrm{y} / \mathrm{t}$, sirasıyla, silindir merkezinden olan boyutsuz yatay ve düşey konumları temsil etmektedirler. Bu şekil aynı zamanda, minikanal içine bir akış bozucu silindirin eklenmesi sonucu meydana gelen akış desenini de resmetmektedir.
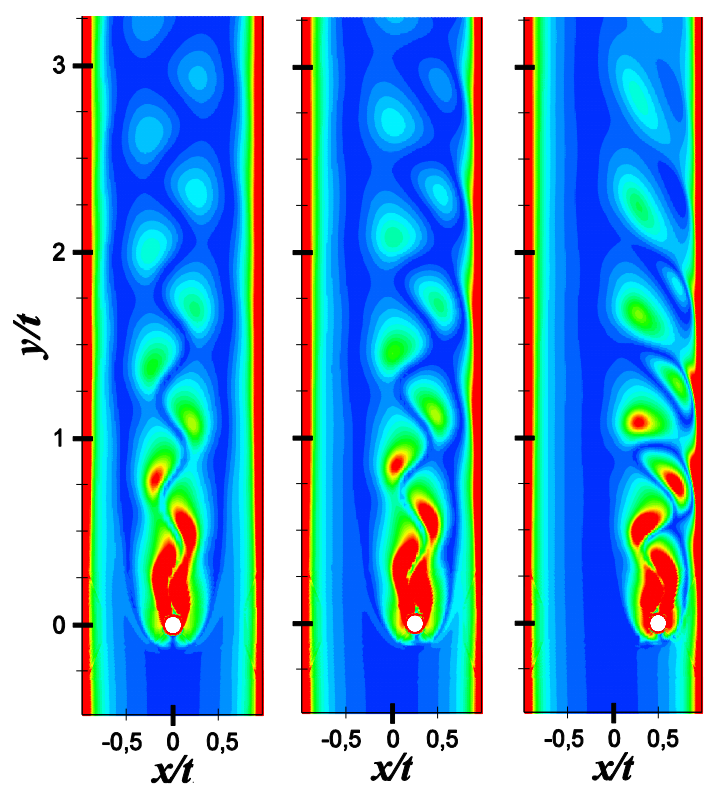

Şekil 4. Farklı boyutsuz mesafe değerleri için (sirasılyla, soldan sağa, $s / t=4 / 8,3 / 8$ ve $2 / 8$ ) düzleme dik eksene ait anlık çevrinti konturları $\left(\omega_{z, \text { maks }}=12000 \mathrm{~Hz}\right.$; $\left.\Delta \omega_{\mathrm{z}}=600 \mathrm{~Hz}\right)$

Akış desenleri bize üç boyutsuz mesafe değerinde de minikanal içerisindeki silindirden çevri dökülmesi olduğunu göstermiştir. Şekle bakıldığında, silindir yüzeyinde gelişen hidrodinamik sınır tabaka içerisinde, silindirden ayrılan kayma tabakaları etrafinda ve kanal yüzeyinde gelişen hidrodinamik sınır tabaka içerisinde yer alan akışkan parçacıklarının dönümlülüklerinin büyük olduğu aşikardır (kırmızı renkli kısım). 
Silindir art izinde görülen Kármán çevri caddesi, silindir cidara yaklaştıkça simetrik yapısını kaybetmeye başlamış ve cidardaki hidrodinamik sınır tabaka ile etkileşimi şiddetlenmiştir. $\mathrm{Bu}$ etkileşim 1sıl sınır tabakayı da etkilemiştir ve zaman-ortalamalı yerel Nusselt sayısının $\left(N u_{\mathrm{y}}\right)$ Şekil 5'teki gibi şekillenmesini sağlamıştır.
Şekil 5'te yer alan $y / L$ ifadesi, kanal başlangicindan olan boyutsuz kanal uzunluğunu ifade etmektedir. Zaman-ortalamal1 yerel 1s1 taşınım katsayısı Eşitlik 9 ile hesaplanabilir.

$\mathrm{h}_{\mathrm{y}}=\left(\frac{1}{\mathrm{t}_{\mathrm{s}}-\mathrm{t}_{\mathrm{b}}}\right) \int_{\mathrm{t}_{\mathrm{b}}}^{\mathrm{t}_{\mathrm{s}}} \mathrm{h} \cdot \mathrm{dt}$

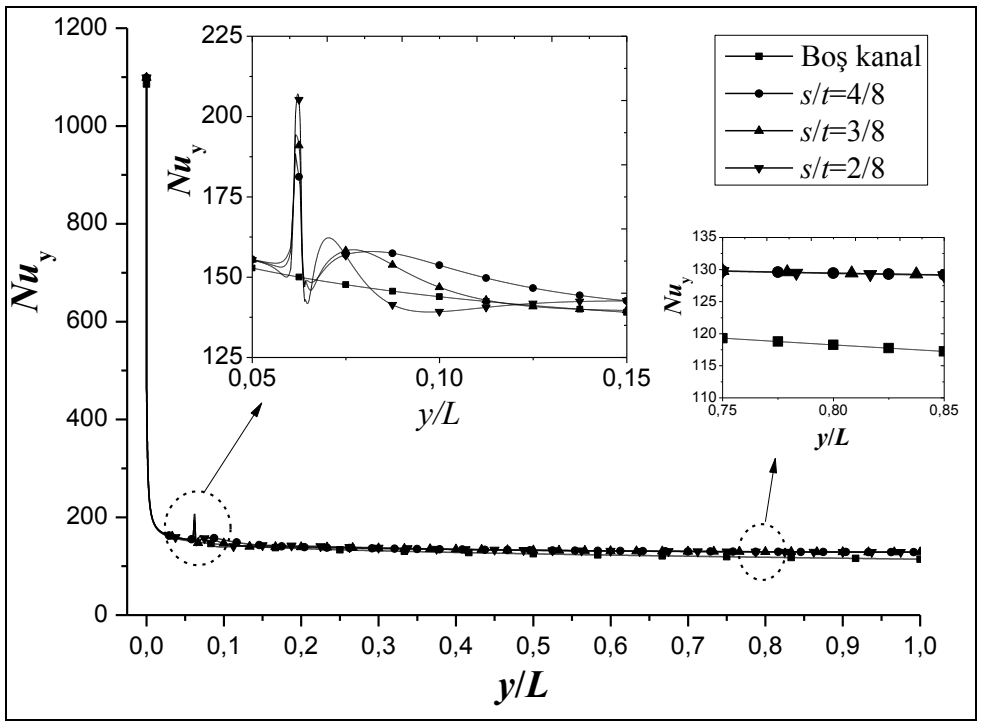

Şekil 5. Zaman-ortalamalı yerel Nusselt sayısının 1sı akısı verilen yüzey uzunluğunca farklı boyutsuz mesafe değerleri için değişimi

Burada yer alan $t_{\mathrm{b}}$, uygun bir benzetim başlangıç zamanını, $t_{\mathrm{s}}$, uygun bir benzetim bitiş zamanını ve $h$ ise anlık 1sı taşınım katsayısını temsil etmektedir. $\mathrm{Bu}$ katsayı ile zaman-ortalamalı yerel Nusselt sayısı da Eşitlik 10 ile elde edilebilir.

$$
\mathrm{Nu}_{\mathrm{y}}=\frac{\mathrm{h}_{\mathrm{y}} \cdot \Delta \mathrm{y}}{\mathrm{k}}
$$

Burada yer alan $\Delta y$, kanal yüzeyindeki kontrol hacmi uzunluğunu, $k$ ise akışkanın 1sı iletim katsayısını temsil etmektedir. İlgili şekle dikkatlice bakılırsa, $N u_{\mathrm{y}}$ 'deki ilk sıçrama tam silindirin bulunduğu konum olan $y / L=0,061$ civarında gerçekleşmiştir. Silindir kanal cidarına ne kadar yakınsa, $N u_{\mathrm{y}}$ 'deki sıçrama da o kadar fazla olmuştur. Bu sıçrama noktasından sonra içerisinde silindir bulunan kanallara ait $N u_{\mathrm{y}}$ değerleri boş kanalınkinden kanal boyunca hep üstte kalmışlardır. Kanal boyunca olan ortalama is1 taşınım katsayısı Eşitlik 11 ile elde edilebilir.

$\mathrm{h}_{\mathrm{ort}}=\frac{1}{\mathrm{~L}} \int_{0}^{\mathrm{L}} \mathrm{h}_{\mathrm{y}} \cdot \mathrm{dy}$

Burada yer alan $L$, kanal uzunluğunu temsil etmektedir. Bu katsayı ile kanal boyunca olan ortalama Nusselt sayısı Eşitlik 12 ile hesaplanabilir.

$$
\mathrm{Nu}_{\text {ort }}=\frac{\mathrm{h}_{\text {ort }} \cdot \mathrm{L}}{\mathrm{k}}
$$

Boş kanal ile kıyaslandığında, içerisinde silindir bulunan kanallara ait $N u_{\text {ort }}$ un boyutsuz mesafelere göre değişimi Şekil 6 içerisinde sunulmuştur. Minikanal yüksekliğinin onda biri kadarlık çapa sahip tek bir silindir ile $s / t$ 'ye bakılmaksızın, 
Tek Taraflı Isıtmaya Maruz Yüksek Şekil Oranlı Minikanallarda Pasif Akış Kontrol Yöntemi Kullanılarak Isı Transferinin Iyileştirilmesi

$N u_{\text {ort }}$ 'da \%5,8'lik bir artış sağlanmıştır. Elbette silindir, kanal içerisinde bir yerel kayba sebebiyet vermektedir. Bunun değerinin ne kadar olduğunu ise Eşitlik 13 ile hesaplanan Darcy sürtünme faktörü ile anlayabilmekteyiz.

$$
\mathrm{f}=\frac{\Delta \mathrm{P}}{\frac{\mathrm{L}}{\mathrm{D}_{\text {hid }}} \cdot \frac{\rho \mathrm{U}_{\text {ort }}}{2}}
$$

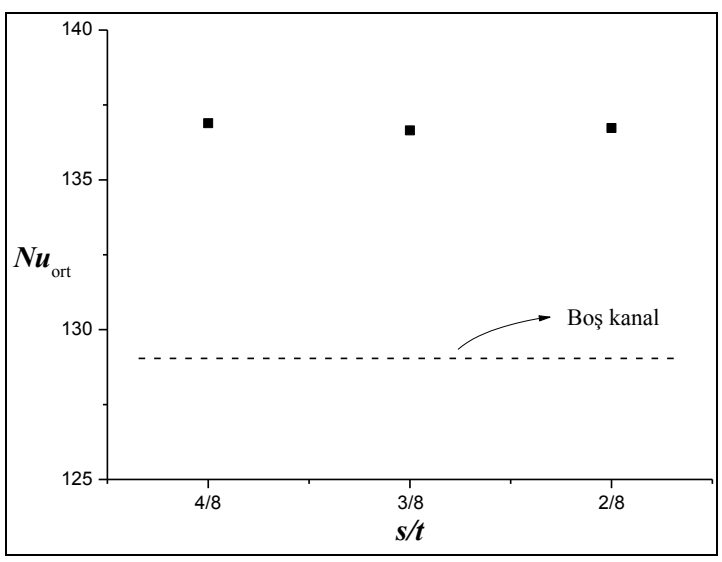

Şekil 6. Kanal boyunca olan ortalama Nusselt sayısının test edilen üç farklı boyutsuz mesafe değeri için değişimi

Burada $\Delta P$, giriş ile çıkış arasındaki basınç farkını,

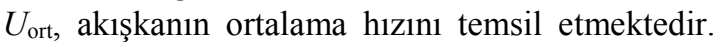
Şekil 7, içerisinde silindir bulunan kanallara ait f'nin boyutsuz mesafelere göre değişimini, boş kanal ile kıyaslamalı olarak vermektedir. Burada $f$ 'deki değişime bakıldığında, silindir cidara yaklaştıkça boru giriş çıkışları arasındaki basınç kaybının azaldığı görülmektedir. Bu durum, çevri dökülmesi ile direkt açıklanabilir. Şekil 4'e baktığımızda, silindir $s / t=4 / 8$ konumunda iken (tam ortada) onun sol ve sağ yüzeylerinden ayrilan kayma tabakaları düzenli çevrilerin şekillenmesine sebep olmaktadır. Silindir cidara yaklaştıkça, onun her iki yüzeyinden ayrılan kayma tabakalarının büyüklükleri arasındaki fark artmakta, bu da daha düzensiz, dolayısıyla da daha kısa ömürlü çevriler meydana gelmesine sebep olmaktadır. Bundan dolayı, burada test edilen $s / t$ aralığı için, dairesel en-kesitli akış bozucu elemanın cidara yakınlığı, ona ait yerel kaybın daha düşük olmasıyla direkt alakalıdır, denilebilir.

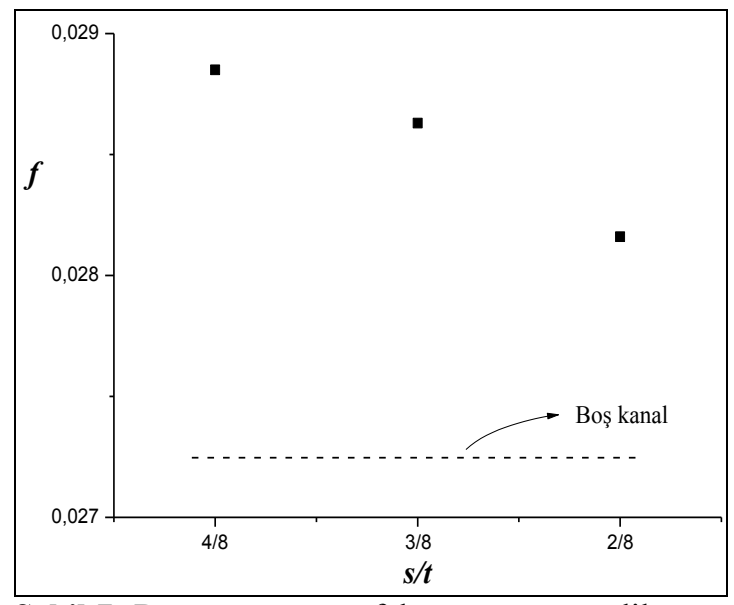

Şekil 7. Darcy sürtünme faktörünün test edilen üç farklı boyutsuz mesafe değeri için değişimi

Isıl performansın $(\eta)$ tanımı ikinci bölümde yapılmış ve onu hesaplamada kullanılan ifade Eşitlik 2'de verilmiştir. Bu eşitlik kullanılarak farklı $s / t$ 'ler için hesaplanan $\eta$ değerleri Şekil 8 içerisinde verilmiştir. Şekil bizlere, en iyi 1sıl performans değerinin $s / t=2 / 8$ konumunda elde edildiğini $(\eta=1,05)$, bu konumda elde edilen değerin diğerlerininkine yakın olduğunu ve kanal içerisine, onun yüksekliğinin neredeyse onda biri çapa sahip bir dairesel silindir yerleştirildiğinde 1sıl performansın 1'den hep büyük olduğunu göstermektedir.

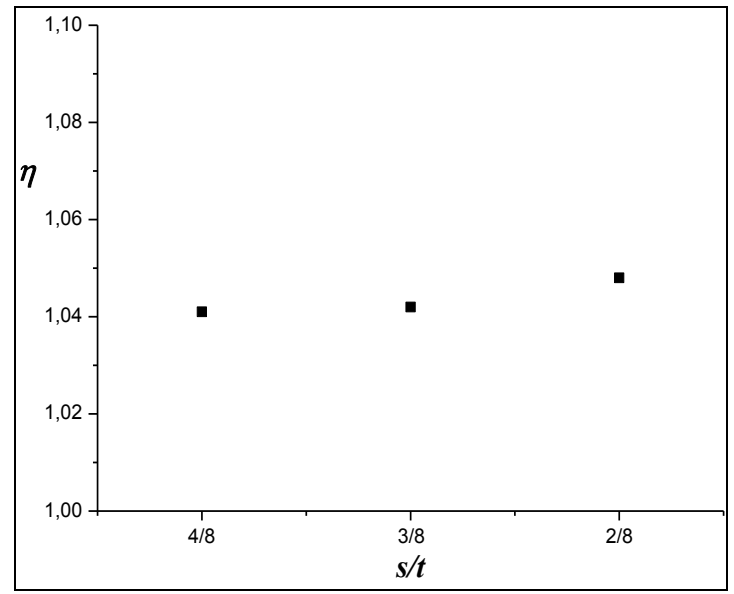

Şekil 8. Isıl performansın test edilen üç farklı boyutsuz mesafe değeri için değişimi 


\section{SONUÇLAR}

Burada gerçekleştirilen sayısal çalışma, Forrest ve arkadaşlarının [1] deneysel çalışmalarında kullandıkları yüksek şekil oranlı minikanalın ısıl performansını, dairesel silindir şeklindeki bir akış bozucu elemanı akış sistemine dahil ederek iyileştirmeyi amaçlamaktadır. Çalışmada, ısıl performansa etkisi incelenen temel parametre, 1sıtılan kanal yüzeyi ile sabit çapa sahip silindir merkezi arası boyutsuz mesafedir $(s / t=2 / 8,3 / 8$ ve 4/8). Çalışma sonuçları, en iyi isıl performans değerinin silindir $s / t=2 / 8 \quad$ konumuna yerleştirildiğinde elde edildiğini $(\eta=1,05)$ göstermiştir. Bunun temel sebebi ise hem silindir ile yüzey arası mesafenin kısalmasından hem de silindirden olan çevri dökülmesinin devam ediyor olmasından dolayı, silindirden ayrılan kayma tabakalarının 1sitılan yüzeyin hem hidrodinamik hem de isıl sınır tabakası ile daha şiddetli etkileşimlerde bulunması olarak belirtilmiştir. $\mathrm{Bu}$ konumda $(s / t=2 / 8)$ elde edilen 1 sil performans değerinin diğerlerininkine $(s / t=3 / 8$ ve $4 / 8)$ yakın olduğu da çalışmadan elde edilen diğer bir sonuçtur. Kanal içerisine, kanal yüksekliğinin neredeyse onda biri çapa sahip bir adet dairesel silindir yerleştirildiğinde, 1 sıl performansın, $s / t$ oranına bakılmaksızın, 1,04'ün altına düşmediğini göstermiştir. Minikanal içerisindeki silindir sayısının artması ile 1sıl performansın daha da artırılabileceği öngörülmüştür.

\section{KAYNAKLAR}

1. Forrest, E.C., Hu, L.W., Buongiorno, J., McKrell, T.J., 2016. Convective Heat Transfer in a High Aspect Ratio Minichannel Heated on one Side, Journal of Heat Transfer, 138, 021704-1.

2. Bilen, K., Cetin, M., Gul, H., Balta, T., 2009. The Investigation of Groove Geometry Effect on Heat Transfer for Internally Grooved Tubes, Appl. Therm. Eng., 29, 753-761.

3. Webb, R.L., 1981. Performance Evaluation Criteria for Use of Enhanced Heat Transfer Surfaces in Heat Exchanger Design, Int. J. Heat Mass Transf., 24(4), 715-726.
4. Samadifar, M., Toghraie, D., 2018. Numerical Simulation of Heat Transfer Enhancement in a Plate-fin Heat Exchanger Using a New Type of Vortex Generators, Appl. Therm. Eng., 133, 671-681.

5. Promvonge, P., Suwannapan, S., Pimsarn, M., Thianpong, C., 2014. Experimental Study on Heat Transfer in Square Duct with Combined Twisted-tape and Winglet Vortex Generators, Int. Commun. Heat Mass, 59, 158-165.

6. Fluent Inc., 2006. Fluent 6.3 User's Guide.

7. Dean, R.B., 1978. Reynolds Number Dependence of Skin Friction and Other Bulk Flow Variables in Two-dimensional Rectangular Duct Flow. J. Fluids Engineering, 100, 215-233.

8. Kandlikar, S.G., Grande, W.J., 2003. Evolution of Microchannel Flow PassagesThermohydraulic Performance and Fabrication Technology. Heat Transfer Eng., 24(1), 3-17.

9. Williamson, C.H.K. 1996. Vortex Dynamics in the Cylinder Wake, 28, 477-539.

10. Liley, P.E., 1984. Steam Tables in SI Units, Private Communication, School of Mechanical Eng., Purdue University, West Lafayette, IN, March 1984.

11. Blasius, H., 1912. Das Aehnlichkeitsgesetz bei Reibungsvorgängen, Z. Ver. Dtsch. Ing., 56(16), 639-643.

12. Colebrook, C.F., 1939. Turbulent Flow in Pipes, with Particular Reference to the Transition Between the Smooth and Rough Pipe Laws, Journal of the Institute of Civil Engineers London, 11, 133-156.

13. Gnielinski, V., 1976. New Equations for Heat and Mass Transfer in Turbulent Pipe and Channel Flow, Int. Chem. Eng., 16(2), 359-368.

14. Petukhov, B.S., 1970. Heat Transfer in Turbulent Pipe Flow with Variable Physical Properties, Adv. Heat Traansfer, 6, 503-564. 
